Supplement of Clim. Past Discuss., 10, 3901-3930, 2014

http://www.clim-past-discuss.net/10/3901/2014/

doi:10.5194/cpd-10-3901-2014-supplement

(C) Author(s) 2014. CC Attribution 3.0 License.

(c) (i)

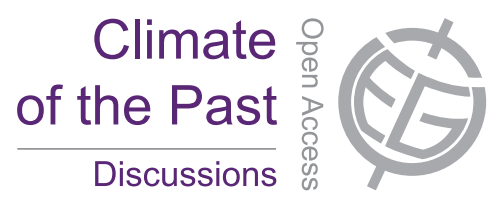

Supplement of

\title{
Spatial climate dynamics in the Iberian Peninsula since 15000 Yr BP
}

P. Tarroso et al.

Correspondence to: P. Tarroso (ptarroso@ cibio.up.pt) 


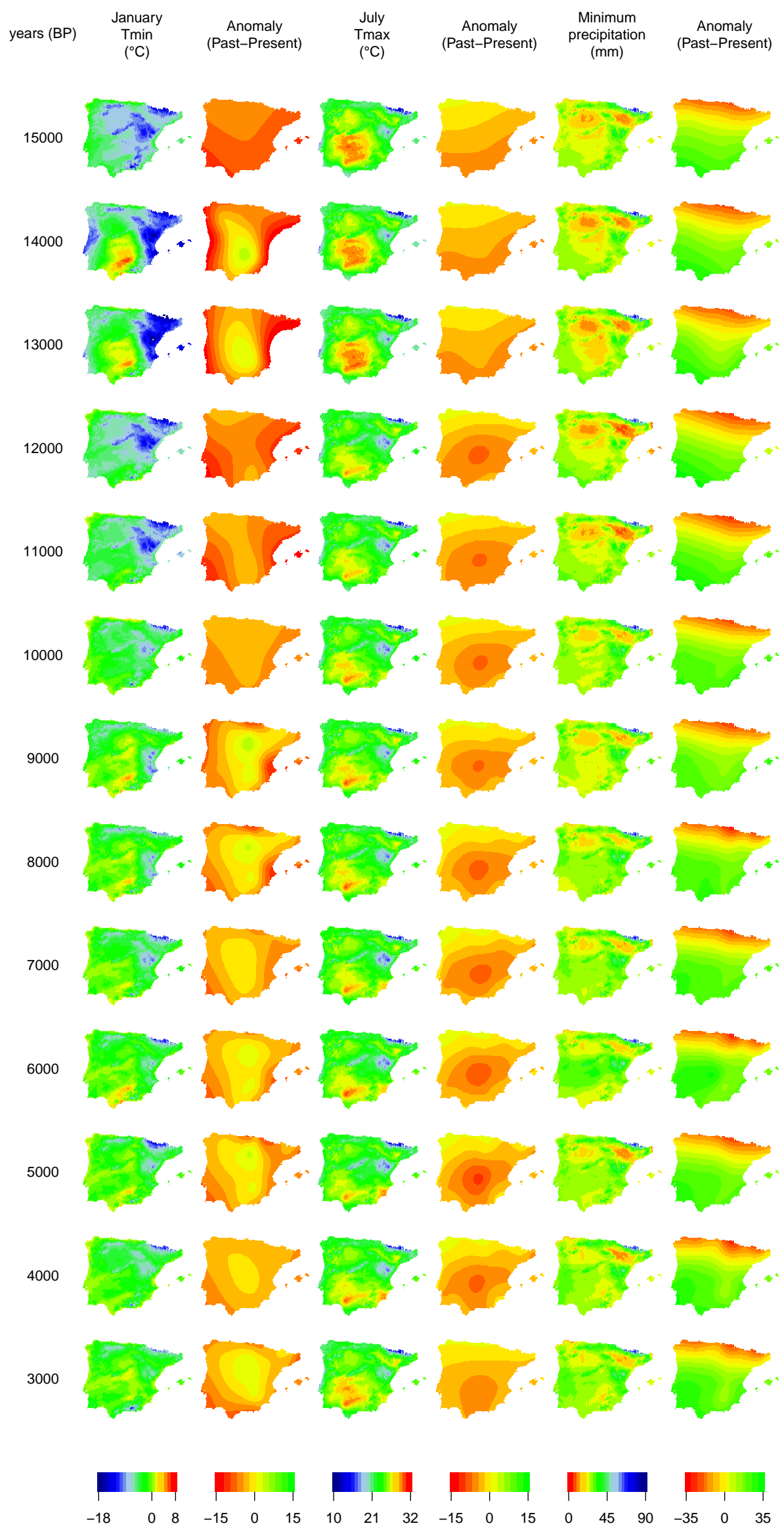

Figure 1: Maps of Tjan, Tjul and Pmin and respective anomalies in the Iberian Peninsula and the Balearic Islands in the past 15 ka. 


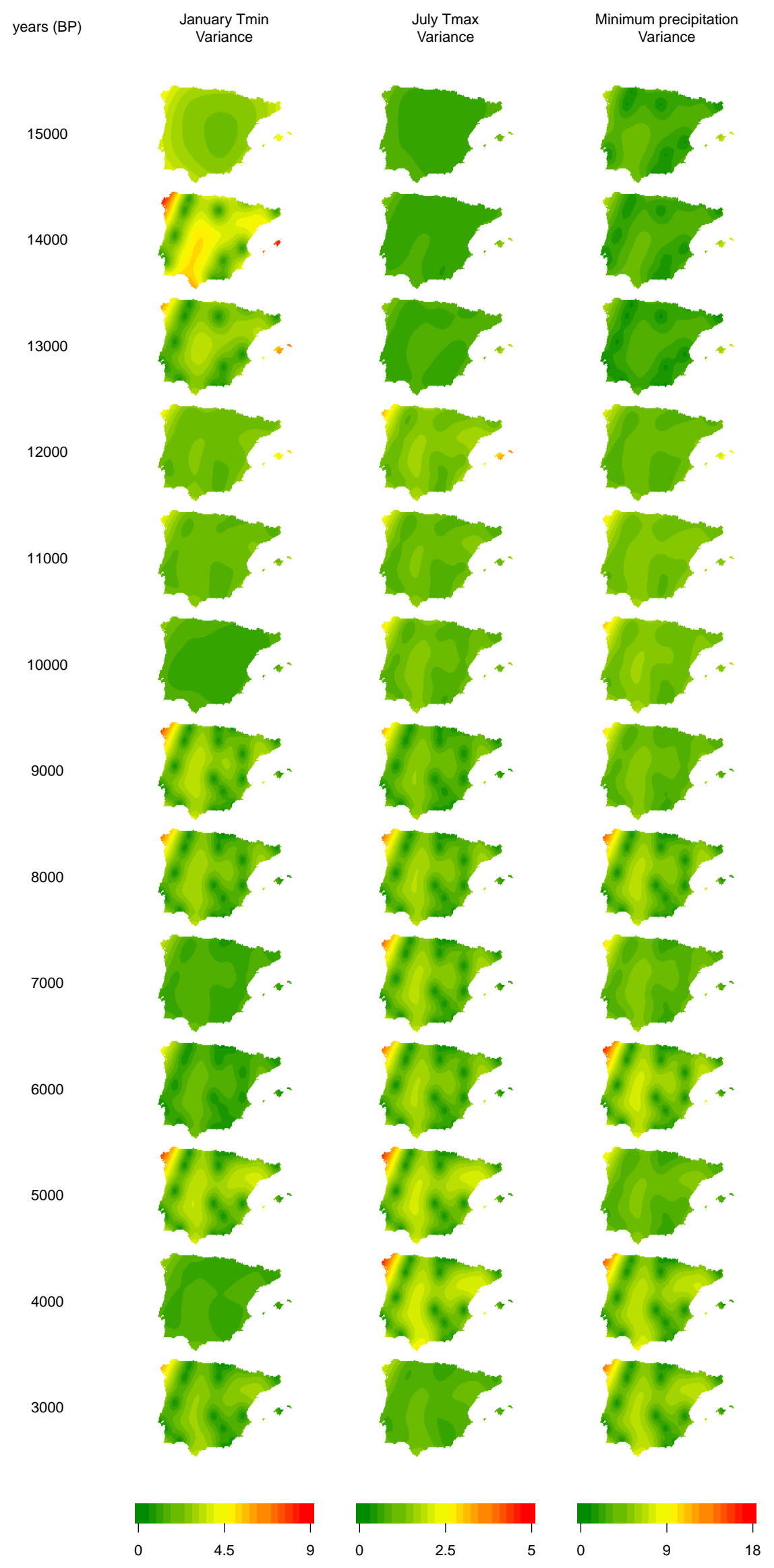

Figure 2: Variance of the spatial interpolation depicting the uncertainty resulting from the sampling coverage. 

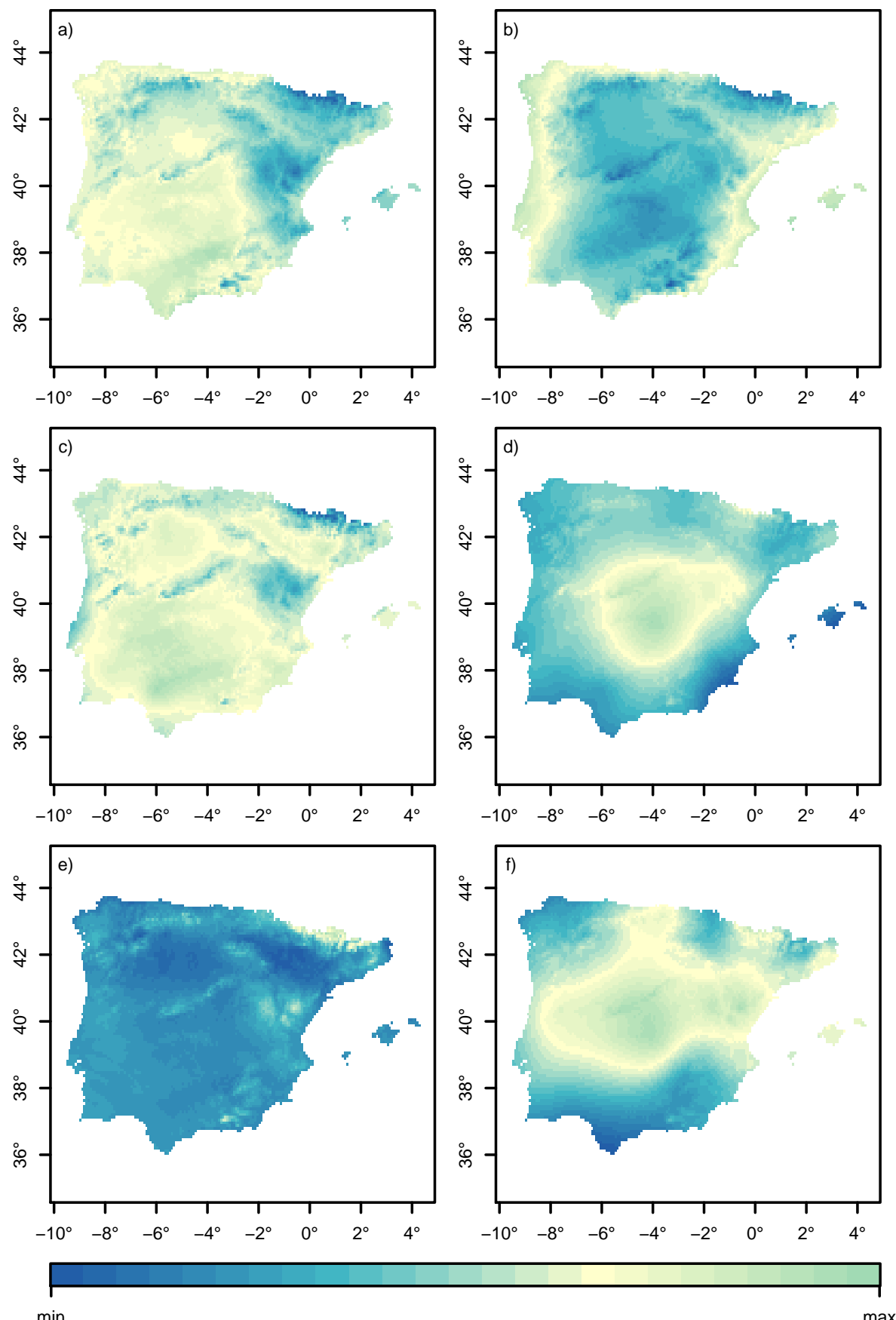

Figure 3: Spatial representations of the fPCA score for the first and second components of Tjan (a and b, respectively); Tjul (c and d) and Pmin (e and f) in the Iberian Peninsula and the Balearic Islands in the past 15 ka. 